\title{
PRICE EARNINGS RATIOS AND ASSET ALLOCATION OVER VARYING INVESTMENT HORIZONS
}

Ronald W. Best, University of West Georgia, Carrollton, GA, USA Charles W. Hodges, University of West Georgia, Carrollton, GA, USA James A. Yoder, University of West Georgia, Carrollton, GA, USA

dx.doi.org/10.18374/RBR-13-1.2

\begin{abstract}
We investigate the impact on the risk-return tradeoff for investors on using price-earnings ratios to choose whether to invest in bonds or stocks. Sharpe ratios are computed for portfolios consisting of $100 \%$ bonds, $100 \%$ stock, and portfolios annually changing between bonds and stocks based on the beginning of year price-earnings ratio. Holding periods from one to 25 years are examined. Simulations are used to create portfolio returns which are used to calculate Sharpe ratios for each holding period. Our results show that the a simple price-earnings ratio based investment rule generates portfolios with higher Sharpe ratios than investing only in bonds or stocks.
\end{abstract}

Keywords: 